\title{
A PRODUÇÃO ESCRITA A PARTIR DO GÊNERO DISCURSIVO NOTÍCIA POR MEIO DE SEQUÊNCIA DIDÁTICA
}

\author{
WRITTEN PRODUCTION FROM THE DISCURSIVE GENRE \\ NEWS BY DIDACTIC SEQUENCE
}

\begin{abstract}
Cristiane Maria da Silva Santana ${ }^{1}$
Resumo: Neste artigo apresentamos o resultado de uma prática pedagógica com o gênero discursivo notícia por meio de sequência didática. A pesquisa foi desenvolvida durante o Mestrado do PROFLETRAS. A pesquisa teve como fundamentação teórica, a concepção de gênero discursivo de Bakhtin e aplicação da sequência didática. Esta investigação de caráter aplicado e intervencionista propôs o desenvolvimento de atividades que contribuíram para a produção e a reescrita, considerando o contexto situacional e sua característica linguística discursiva. Após a intervenção, verificamos que os alunos participantes apresentaram um avanço significativo.
\end{abstract}

Palavras-chave: gênero discursivo; notícia; sequência didática; produção escrita.

\begin{abstract}
In this article, we present the result of a pedagogical practice with the discursive genre news through a didactic sequence. The research was developed during the Master of the PROFLETRAS. The research was based on the Bakhtin's theory of discursive gender and the application of the didactic sequence. This research of applied and interventionist nature proposed the development of activities that contributed to the production and rewriting, considering the situational context and its linguistic - discursive characteristic. After the intervention, we found that the participants had a significant advancement.
\end{abstract}

Keywords: discursive genre; news; sequence didactic; written production.

\section{Introdução}

Trabalhar com os gêneros discursivo-textuais ${ }^{2}$ em sala de aula é um dos grandes desafios para os professores de turmas iniciais da educação básica. São diversos os fatores que contribuem para que este processo não aconteça de forma significativa, destacamos como um dos fatores a falta de conhecimento por parte de alguns professores do gênero discursivo a ser trabalhado e produzido, ou seja, o conhecimento referente à estrutura, propósito comunicativo e esfera social. Outro fator que também destacamos é a presença de diversos gêneros

\footnotetext{
1 Docente da educação básica. Mestre em Letras pelo PROFLETRAS/UFPB. E-mail: professoracristianemaria@gmail.com

${ }^{2}$ Essa denominação gêneros textuais não é consensual e poderá ser também gêneros do discurso ou gêneros discursivos. Utilizaremos gênero discursivo/textual.
} 
discursivos nos livros didáticos, mas, de forma ainda muito superficial, não favorecendo refletir sobre as relações de produção do gênero discursivo na prática.

Sabemos que nossos alunos vivem em um contexto letrado, isto é, permeado por letras, números, imagens, movimentos e assim fazem uso da leitura e da escrita mesmo sem saber ler, através do conhecimento de mundo e da necessidade de interagir na sociedade. A criança antes de começar a frequentar a escola possui uma série de conhecimentos sobre a língua escrita decorrente da interação com pessoas já alfabetizadas em diferentes contextos. Mesmo as que vivem em zonas rurais ou urbanas com pessoas não alfabetizadas, possuem algum conhecimento sobre a função da escrita. É na escola que o aluno precisa entender e aprender a usar a escrita como função social.

Os Parâmetros Curriculares Nacionais - PCN (BRASIL,2001) também recomendam o desenvolvimento de atividades no qual o uso dos gêneros discursivos oportunize a prática de leitura e escrita associados ao uso da linguagem reflexiva. Embora os alunos tenham acesso do ponto de vista da leitura destes gêneros discursivos, no que se refere à produção escrita, essa diversidade praticamente não existe na sala de aula.

Assim, neste artigo apresentaremos uma prática didática, com ênfase na importância do trabalho com leitura e produção textual, que resultou em uma experiência exitosa com o gênero discursivo Notícia por meio de sequência didática. A pesquisa foi desenvolvida durante o Mestrado Profissional em Letras (PROFLETRAS) em uma Escola Pública e os resultados obtidos elucidam o trabalho com o gênero discursivo notícia por ser um gênero de uso social com diversos temas de interesse ao público em geral e de circulação em suporte impresso e digital.

A proposta teórica - metodológica assumida nessa intervenção pedagógica pautou-se na perspectiva Bakhtiniana, com o gênero discursivo/textual notícia por meio do procedimento da sequência didática. No que tange ao conhecimento e características do gênero notícia, nos embasamos nos estudos de Nascimento (2009), nos Manuais de Redação em que discorreremos sobre a estrutura da notícia, conteúdo temático, estilo e público alvo.

Nessa intervenção consideramos alguns aspectos relacionados à produção da notícia no contexto social do aluno. A escolha do gênero notícia também se deve ao fato que este gênero favorece muito bem a investigação com respeito ao seu uso linguístico e social.

Assim, as possibilidades de trabalhar com este gênero vão além das informações explícitas no seu conteúdo. Atendendo ao nível de capacidades de escrita dos alunos participantes, exploramos apenas a produção do título e do lead, o primeiro parágrafo da 
notícia. Dessa forma a Escola como um espaço democrático que visa à formação de sujeitos reflexivos e críticos, os alunos tiveram a oportunidade de produzir textos concretos, reais, visto que, os gêneros discursivos são formas de agir em sociedade.

\section{Fundamentação teórica}

\subsection{Gêneros textuais/discursivos}

Os gêneros discursivo-textuais se apresentam como instrumentos eficazes no processo de aprendizagem, pela sua diversidade, amplitude e por fazer necessárias em diversas situações comunicativas. Pautamos nossa base teórica na perspectiva Bakhtiana onde o autor afirma que a linguagem só se realiza por meio dos gêneros. Nesse sentido, inclusive, é impossível enumerá-los, diante da diversidade das atividades comunicativas que compõem a linguagem e suas práticas. Segundo Bakhtin (2011), há uma diversidade de gêneros do discurso e existe um específico para cada situação comunicativa. Assim, não precisamos criar a cada momento um gênero para comunicação. Em suas palavras Bakhtin destaca:

A riqueza e a diversidade dos gêneros do discurso são infinitas porque são inesgotáveis as possibilidades da multiforme atividade humana e porque em cada campo dessa atividade é integral o repertório de gênero do discurso, que cresce e se diferencia à medida que se desenvolve e se complexifica um determinado campo. (BAKHTIN, 2011, p.262).

Entendemos assim que, as práticas de linguagens definem a utilização de um determinado gênero, ou seja, no processo de interação o falante escolhe o gênero adequado a sua situação comunicativa. Para Bakhtin a linguagem é um fenômeno social, histórico e dialógico, em que o enunciado é uma unidade de comunicação verbal. Segundo o autor aprender a falar, é aprender a estruturar enunciados (por que falamos por enunciados e não por orações isoladas, descontextualizadas). Utilizamos os gêneros do discurso para organizar os nossos enunciados e os modos de dizer. Sobre isso, Bakhtin (2011) ressalta:

\footnotetext{
Nós aprendemos a moldar o nosso discurso em formas de gêneros e, quando ouvimos o discurso alheio, já adivinhamos o seu gênero pelas primeiras palavras, advínhamos um determinado volume (isto é, uma extensão aproximada do conjunto de discurso), uma determinada construção composicional, prevemos o fim, isto é, desde o início temos a sensação do conjunto do discurso que em seguida apenas se diferencia no processo da fala. (BAKHTIN, 2011, p.283).
}

Observa-se que todas as esferas da atividade humana estão relacionadas à utilização da língua seja na esfera da oralidade, seja na esfera da escrita, de textos multimodais, tendo em vista a presença midiática dos gêneros textuais emergentes na mídia virtual. Diferentes 
gêneros circulam na vida cotidiana exigindo conhecimento do seu uso em diferentes contextos sociais. É necessário criar oportunidades para situar os diferentes gêneros do discurso em seu campo de atuação.

Segundo o autor toda compreensão da fala viva, do enunciado vivo é de natureza ativamente responsiva, toda compreensão é prenhe de resposta, e nessa ou naquela forma gera obrigatoriamente: o ouvinte torna-se falante. Assim, ter um interlocutor é dirigir-se a alguém, o que evidencia uma particularidade constitutiva do enunciado, sem a qual não há, e nem poderia haver enunciado. Cada enunciado é um elo na corrente complexamente organizada de outros enunciados. (BAKHTIN, 2011, p.272).

Bakhtin chama de gêneros discursivos primários (simples), frutos de interações verbais, ou seja, espontâneas, que não são elaboradas. Segundo Bakhtin os gêneros secundários, estão relacionados às esferas culturais, estes são elaborados, principalmente na sua escrita.

Por esse limiar, Koch \& Elias (2013), fundamentadas nas pesquisas de Bakhtin (2011), defendem a ideia de que o envolvimento dos indivíduos com as diferentes práticas sociais favorece o desenvolvimento de uma competência metagenérica, possibilitando a apropriação e o entendimento dos diversos contextos dos gêneros discursivos.

Essa competência, segundo as autoras são de suma importância, pois, guiará o usuário da língua a exercer com prioridade a produção e a compreensão dos diferentes gêneros. Ainda, segundo os estudos de Kock \& Elias (2013), é essa perspectiva que possibilita aos sujeitos de uma interação não só diferenciar os diversos gêneros, como também identificar as práticas sociais que os solicitam. Ainda sobre interação Bakhtin (2003) relata:

Todas as esferas da atividade humana, por mais variadas que seja, estão relacionados com a utilização da língua. Não é de surpreender que o caráter e os modos dessa utilização sejam tão variados com as esferas da atividade humana [...]. O enunciado reflete as condições específicas e as finalidades de cada uma dessas esferas, não só por seu conteúdo temático e por seu estilo verbal, ou seja, pela seleção operada nos recursos da língua - recursos lexicais, fraseológicos e gramaticais, mas também, e, sobretudo, por sua construção composicional. (BAKHTIN, 2003, p.279).

Com base no posicionamento desse autor, entendemos que toda produção quer oral, quer escrita, está embasada em formas- padrões relativamente estáveis. Nesse sentido, os gêneros do discurso favorecem o desenvolvimento das atividades nas situações comunicativas, contribuindo para os aprendizes como uma referência para suas produções. 
Sendo a língua um fenômeno sócio histórico, suas manifestações (enunciados concretos, exemplares de gêneros discursivos) não podem ser dissociadas de seus falantes e de seus atos, das esferas sociais, dos valores ideológicos (BAKHTIN, 2003).

\section{$1.2 O$ gênero discursivo/textual notícia}

Como dissemos na introdução, os Parâmetros Curriculares Nacionais - PCN (BRASIL, 2001) recomendam a utilização dos gêneros discursivo-textuais como objetivo de ensino para a prática de leitura e escrita, associados à reflexão sobre o uso social da linguagem. Em meio à diversidade dos gêneros, escolhemos trabalhar com o gênero notícia. Mas, afinal o que é uma notícia? Vejamos a seguinte citação: O que é notícia? Para reduzir a definição ao mínimo possível, diríamos que notícia é a técnica de relatar um fato. Para sermos ainda mais concisos, diríamos simplesmente que notícia é o relato, não o fato. (LUSTOSA, 1996, p.17).

Com base na conceituação apresentada, percebemos o gênero notícia, como um relato de um fato, ou seja, não é o fato em si, mas o relato do acontecimento que se contextualiza em uma notícia. Segundo Nascimento (2010) "é importante preparar o aluno para ir além do óbvio no gênero notícia, tornando-o capaz de ler e analisar como o fato é relatado e com que intenção o relato é feito". (NASCIMENTO, 2010, p. 6).

Ainda com base nos preceitos de Nascimento (2009) "noticiar é, portanto, o relato do fato, cabendo à análise para a reportagem, que é mais interpretativa”. Entendemos assim, que a notícia é o relato do fato, ou seja, a situação real como ocorreu e a reportagem são construídos de vozes em torno da notícia.

Segundo o Manual de Redação e Estilo de O Globo (2011), no que diz respeito à estrutura da notícia, "o esquema clássico é o da pirâmide invertida: alimenta-se o início da matéria com os fatos mais relevantes, e o conteúdo dos parágrafos que se seguem vai decrescendo em importância”. (GARCIA 2001, p.35). De acordo com o referido documento, a notícia deve responder a seis perguntas: Quem? Quê? Quando? Onde? Por quê? Como? 


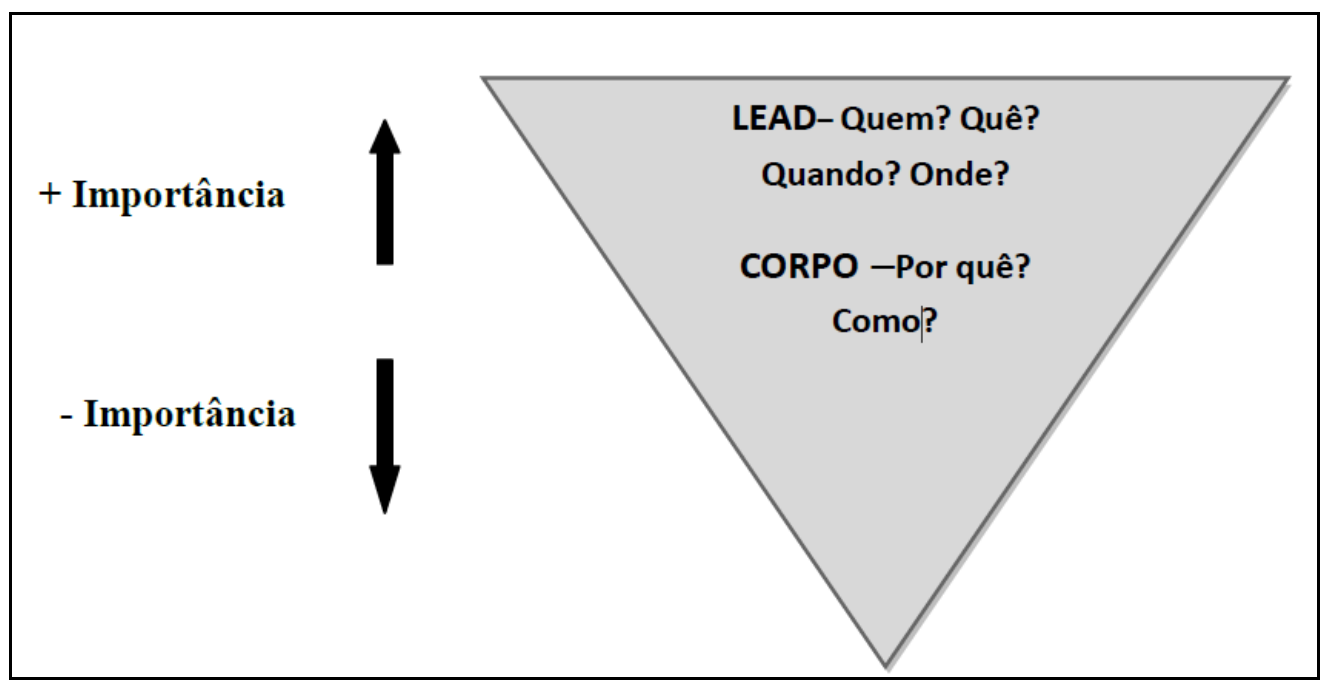

Fonte: Imagem do Manual de Redação

Na pirâmide invertida os elementos: Quem? Refere-se aos sujeitos envolvidos no relato; Quê? Refere-se ao fato noticiado, ou seja, o que aconteceu; Quando? Diz respeito ao tempo. Onde? Refere-se ao lugar onde aconteceu/acontece o fato ( $L E A D)$. Por quê? Diz respeito às circunstâncias e Como? Refere-se ao modo como aconteceram os fatos. (Corpo da notícia).

Para Lage (2004), a notícia jornalística é um gênero no qual predominam as estruturas narrativas, mas os jornais não se limitam apenas a narrar os fatos que aconteceram, eles também relatam como e porque aconteceu determinado fato. De acordo com os Manuais de Redação a notícia deve ser inédita e verdadeira. Erbolato (1991, p.55), contribui afirmando que a notícia deve ser "recente, inédita, verdadeira, objetiva e de interesse público". De acordo com o Manual de Redação e estilo o gênero notícia apresenta a seguinte estrutura:

1. O título - segundo o manual de redação e estilo - O Globo (2001, p.51), o título refere-se ao "anúncio da notícia, concentrado no fato que provavelmente despertará mais atenção".

2. O título auxiliar - tem como função complementar o título principal, ou seja, acrescentar informações que o torne mais atrativo.

3. O Lead - refere-se ao primeiro parágrafo da notícia e normalmente sintetiza o que há de mais importante no texto.

4. Corpo da notícia - segundo Lage (2004), o corpo de uma notícia também denominado documentação, complementa o lead, ou seja, expõem em detalhes as informações. O manual de redação e estilo - O Globo (2001) declara: 
O bom lead é aquele que faz o leitor continuar a ler. Exige-se apenas que não haja fraude: o que o lead promete, o resto da matéria precisa apresentar. E aquilo que o lead diz ser importante deve receber no desenvolvimento da matéria, destaque e espaço correspondente a essa importância. (MANUAL DE REDAÇÃO, 2001, p.32).

Observamos com esta afirmação que o lead deve conter informações verdadeiras e que todas as informações estejam no corpo da notícia. Ainda, segundo Lage, do ponto de vista da estrutura, a notícia é definida como "o relato de uma série de fatos a partir do fato mais importante ou interessante; e de cada fato, a partir do aspecto mais importante ou interessante". (LAGE, 2004).

Assim, a notícia é um gênero textual/discursivo do universo jornalístico e, conforme Nascimento (2010), é considerado como "um gênero que possui uma função social bastante específica, quer seja de relatar fatos ou acontecimentos da vida social".

Deste modo, com base no construto teórico e na importância de trabalhar com o gênero discursivo notícia, desenvolvemos uma intervenção numa escola pública. A intervenção foi realizada numa turma de $3^{\circ}$ ano (turma da pesquisadora) do ensino fundamental. A faixa etária entre 7 e 8 anos, contamos com um total de 10 produções para análise. As ações de intervenção pautou-se na sequência didática proposta pela autora Lopes Rossi (2002).

\section{Metodologia}

\section{1 Sequência didática}

Orientar as práticas de ensino da língua nos leva a repensar a prática e adotar uma postura frente as situações significativas de aprendizagem. Nesse sentido adotar a concepção de gêneros discursivos contribui para o desenvolvimento da competência comunicativa. A sequência didática consiste em uma estratégia válida tanto para a produção oral como para produção escrita de diferentes gêneros discursivos.

Os autores Dolz, Noverraz e Schneuwly (2004) dedicam total atenção ao estudo do gênero, pautado no caráter sociodiscursivo de Bakhtin para os gêneros discursivos. Segundo os autores, "uma sequência didática tem praticamente, a finalidade de ajudar o aluno a dominar melhor um gênero de texto, permitindo-lhes, assim, escrever ou falar de maneira mais adequada numa dada situação de comunicação". Os autores chamam a atenção para o fato de que, durante a elaboração das sequências didáticas, deve-se analisar os alunos envolvidos, suas capacidades e dificuldades e assim adequar a escolha do gênero e até mesmo 
simplificar a atividade para que os alunos possam desenvolver e progredir nas suas atividades, seja elas de leitura, de escrita ou de reflexão linguística em torno de um gênero textual.

Lopes-Rossi (2002) também traz uma importante contribuição com respeito ao desenvolvimento de uma sequência didática. A autora enfatiza que qualquer projeto de leitura e escrita deve iniciar-se por um estudo das condições de produção e circulação. Em sua proposta de projeto com sequências didáticas ela elenca as etapas para o trabalho de produção textual. Com base na metodologia apresentada por Lopes- Rossi (2002), organizamos as atividades didáticas sequenciadas, seguindo as orientações propostas e realizando as adequações necessárias para o contexto da pesquisa.

O quadro a seguir apresenta a divisão dos módulos segundo Lopes - Rossi (2002) com as situações elaboradas com propósito de leitura do gênero discursivo, apropriação, produção e divulgação ao público.

Quadro 1 - Esquema geral de projeto para produção escrita de gêneros discursivos na escola segundo Lopes Rossi.

\section{INICÍO DO PROJETO}

Explicitação do objetivo final do projeto quanto à divulgação ao público dos textos a serem produzidos.

\begin{tabular}{|c|c|}
\hline MÓDULOS DIDÁTICOS & SEQUÊNCIAS DIDÁTICAS ELEBORADAS VISANDO \\
\hline $\begin{array}{l}\text { MÓDULO 1 } \\
\text { Leitura para apropriação das } \\
\text { características típica do } \\
\text { gênero discursivo }\end{array}$ & $\begin{array}{l}\text { Ações - Atividades de leitura, comentários e discussões de } \\
\text { vários exemplares do gênero para conhecimento de suas } \\
\text { características sociocomunicativas e composicionais (verbais } \\
\text { e não verbais), de sua organização retórica e de seu estilo. }\end{array}$ \\
\hline $\begin{array}{l}\text { MÓDULO 2 } \\
\text { Produção escrita do gênero de } \\
\text { acordo com suas produções } \\
\text { de condição típica }\end{array}$ & $\begin{array}{l}\text { Atividades seguindo o modo de produção do gênero nas } \\
\text { situações reais: } \\
>\text { Planejamento da produção (definição do assunto, esboço } \\
\text { geral, forma de obtenção de informações, recursos } \\
\text { necessários). } \\
>\text { Coleta de informações. } \\
>\text { Produção da primeira versão de acordo com movimentos } \\
\text { retóricos típicos do gênero ou possíveis, caso não haja uma }\end{array}$ \\
\hline
\end{tabular}




\begin{tabular}{|c|c|}
\hline & $\begin{array}{l}\text { padrão. } \\
>\text { Correção colaborativa do texto, indicando aspectos a ser } \\
\text { melhorados. } \\
>\text { Produção da segunda versão, atendendo às indicações de } \\
\text { correção. } \\
>\text { Revisão do texto } \\
>\text { Diagramação da versão final, de acordo com o suporte } \\
\text { para circulação. }\end{array}$ \\
\hline \begin{tabular}{|l} 
MÓDULO 3 \\
Divulgação ao público de \\
acordo com a fórmula típica \\
de circulação do gênero.
\end{tabular} & $\begin{array}{l}\text { Série de providências para efetivar a circulação da produção } \\
\text { dos alunos fora da sala de aula ou mesmo na escola. }\end{array}$ \\
\hline
\end{tabular}

No módulo I a autora enfatiza a importância da leitura para a apropriação das características típicas do gênero em estudo. Segundo Lopes - Rossi (2002) é necessário conhecer o gênero começando pela leitura, apropriando-se dos aspectos discursivos para compreensão de sua organização textual. A sequência de leitura em torno do gênero que se pretende produzir contribuirá para o desenvolvimento da prática de leitura e proporcionará situações de produção.

Quanto ao módulo II a autora aborda a produção escrita do gênero de acordo com suas condições de produção típica. Nessa etapa ela propôs uma série de atividades de produção: planejar a produção textual, a elaboração do esboço, como obter as informações, quais recursos deverão providenciar.

No terceiro e último módulo ocorre à divulgação ao público. Nessa etapa deve ser organizado o ambiente para divulgação das produções dos alunos. Requer providências do local, organização do material para exposição. Conforme a autora revela que esta etapa é de grande satisfação para todos os envolvidos no projeto. Ela continua "sentimentos como emoção e orgulho encerram um processo que, certamente, contribui muito para o desenvolvimento das habilidades comunicativas dos alunos e para a ampliação de seu conhecimento de mundo". (LOPES- ROSSI, 2002).

\subsection{O trabalho em sala de aula por meio da sequência didática}


Considerando a importância deste processo na escola, vivenciamos situações reais de produção textual, assim, por meio do desenvolvimento das etapas da sequência didática, obtivemos as produções para análise e tomada de decisões quanto aos procedimentos de intervenção.

O corpus que constitui a investigação foi produzido por alunos participantes da turma de $3^{\circ}$ ano do ensino fundamental que se encontra em fase de desenvolvimento das capacidades de leitura e da escrita. Considerando as dificuldades nessa fase, produzimos o título e o lead da notícia, analisando os aspectos referentes à estrutura do lead.

A pesquisa de natureza descritiva e intervencionista, em que, por meio da metodologia de sequência didática desenvolvemos as etapas elaboradas para a produção dos textos. Apresentamos a situação comunicativa, a proposta de construir um jornalzinho para a Escola com notícias reais do cotidiano do aluno e a exposição no final.

As atividades que desenvolvemos envolveu apresentação de diversos textos (notícias) em jornais impresso de circulação. Leitura e manuseio do caderno do jornal. Durante as leituras, chamamos a atenção para os títulos das notícias, o lead, atendendo a estrutura de apresentação; Quem? Quê? Quando? E onde? Aspectos composicionais do lead.

Após diversas leituras, manuseio de jornais os alunos aceitaram o desafio de realizar a primeira produção. Listamos uma série de problemas que no momento estavam acontecendo na sua cidade e no seu bairro. Durante a intervenção, em sala de aula, disponibilizamos em um varal diversos jornais para que os alunos tivessem o maior contato com o gênero notícia. A partir dessa compreensão partimos para a primeira produção do título e do lead.

De posse das primeiras produções passamos a analisar até que ponto eles compreenderam a estrutura composicional do gênero, ou seja, eles produziram o título e o lead com base nas orientações e modelos de notícias apresentados em sala de aula. Embora tenhamos identificados outros problemas (referente ao domínio sintático, morfológico, lexical e fonológico) consideramos o resultado da produção referente aos aspectos composicionais do título e do lead. Constam no quadro a seguir 5 das 10 produções desenvolvidas em sala de aula e contidas na dissertação.

\subsection{Primeiras produções dos alunos}

Quadro 2. Primeiras produções

\begin{tabular}{|l|l|l|}
\hline Numeração & Transcrição do título da & Transcrição do lead \\
\hline
\end{tabular}




\begin{tabular}{|l|l|l|}
\hline \multicolumn{1}{|c|}{ notícia } & \\
\hline Texto - 1 & Não escreveu o título & $\begin{array}{l}\text { Os professores não estão indo para Escola que o } \\
\text { Prefeito não esta pagando as Escolas }\end{array}$ \\
\hline Texto - & A greve dos professores & $\begin{array}{l}\text { Os professores não estão indo para escola por } \\
\text { calsa dos prefeitos que não estão pagando as } \\
\text { crianças estão sem aulas porqué os professores } \\
\text { não estão recebendo salarios }\end{array}$ \\
\hline Texto - 3 & Política Eleição & $\begin{array}{l}\text { Nodia2otuboaspessoasvaeescolheroperfedocidade } \\
\text { naruapacacarrodesonacicaZepalo }\end{array}$ \\
\hline Texto - 5 & Lixo & $\begin{array}{l}\text { Na ruas tão muta polisão soprefeto não pagra } \\
\text { nasepreza selixo tacas a degue matano as pessoas } \\
\text { não pode xaágua parada }\end{array}$ \\
\hline Texto - 8 & Saúde & $\begin{array}{l}\text { Crianças de 15 anos pra baixo deve toma a vacina } \\
\text { comtra HPV as vacinas a cabam no dia 30 de } \\
\text { Setembro. }\end{array}$ \\
\hline
\end{tabular}

Fonte: Produções dos alunos

\section{Proposta de intervenção}

Ao analisarmos as primeiras produções identificamos muitos problemas de ordem gramatical e de segmentação de palavras, mas, ressaltamos que nosso propósito pautou-se em observar a interação com o gênero notícia, a apropriação e a oportunidade dos alunos de produzirem seus textos reais, ou seja, analisamos do ponto de vista discursivo.

Para identificar as dificuldades, os participantes formaram grupos e conforme a autora Lopes Rossi orienta em seus módulos, realizamos uma correção colaborativa junto com os alunos, lendo cada produção. A revisão colaborativa consiste no momento em que colegas e professor atuam como leitores e sugerem correções ou sugestões para melhorias nos textos. No momento eles contribuíra com sugestões para reescrita dos textos. Essa proposta da autora oportuniza uma maior interação entre os pares e favorece a construção do conhecimento.

Os alunos trocaram os textos entre si e tentaram identificar os "erros" que poderiam ser corrigidos. Algumas correções foram necessárias e realizadas nos textos para estabelecer o 
sentido e o propósito comunicativo da notícia. Segue o quadro 3 com as transcrições da segunda produção após a correção colaborativa e as correções mais relevantes.

Quadro 3 - Transcrição da segunda produção do título e do lead

\begin{tabular}{|c|c|c|}
\hline Numeração & Transcrição do título & Transcrição do lead \\
\hline Texto 1 & $\begin{array}{l}\text { Escolas ficam em greve por falta de } \\
\text { pagamento }\end{array}$ & $\begin{array}{l}\text { Em Santa Rita os professores } \\
\text { não estão indo para escola } \\
\text { porque o prefeito não está } \\
\text { pagando os salários dos } \\
\text { professores. A sala de aula fica } \\
\text { vazia. Não se sabe quando as } \\
\text { aulas vão voltar. }\end{array}$ \\
\hline Texto 2 & Greve dos professores & $\begin{array}{l}\text { Os professores não estão indo } \\
\text { para escola por causa dos } \\
\text { salários atrasados. As crianças } \\
\text { estão sem aula. pode volta depois } \\
\text { da eleição. }\end{array}$ \\
\hline Texto 3 & Eleições 2016 & $\begin{array}{l}\text { No dia } 2 \text { de outubro as pessoas } \\
\text { vão escolher o prefeito da } \\
\text { cidade. Na rua de Várzea Nova } \\
\text { passa carro de som com música } \\
\text { de Zé Paulo. }\end{array}$ \\
\hline Texto 5 & Lixo na rua & $\begin{array}{l}\text { Nas ruas de Várzea Nova tem } \\
\text { muito lixo. O carro de lixo não } \\
\text { passa porque o prefeito não } \\
\text { pagou a empresa. as pessoas } \\
\text { ficam doentes com a dengue }\end{array}$ \\
\hline Texto 8 & Saúde & $\begin{array}{l}\text { Criança abaixo de } 15 \text { anos deve } \\
\text { tomar a vacina conta HPV. As } \\
\text { vacinas acabam no dia } 30 \text { de } \\
\text { Setembro para tomar vacina tem } \\
\text { que levar o cartão de vacina. }\end{array}$ \\
\hline
\end{tabular}

Fonte: Segunda produção dos alunos - reescrita. 


\subsection{Resultados obtidos}

Como é possível perceber, a segunda produção apresentou mudanças significativas, embora, não encontrássemos a presença do verbo no título, acreditamos que ocorreu por ainda não haver o conhecimento da classe gramatical. A produção foi individual estando à transcrição idêntica a produção original, visto que, a segunda produção é o resultado da compreensão do aluno quanto aos aspectos organizacionais e estruturais do gênero textual/discursivo notícia. Reconhecemos que ao realizar a reescrita houve um avanço significativo nas produções. Precisamos compreender que o processo de escrever é contínuo e demanda tempo. Os gêneros discursivos/textuais se apresentam como instrumentos eficazes, no entanto, sua eficiência depende de um bom planejamento, não basta conhecer o gênero, é preciso saber produzir e fazer o uso social.

Podemos constatar que, conforme Lopes- Rossi (2002) afirma a revisão e a correção colaborativa dos textos produzidos pelos alunos, envolvendo o professor, outros colegas da sala, são atividades muito importantes no processo de aprendizagem da escrita. "A primeira versão não fica perfeita, a opinião dos colegas contribui para a organização e favorece também ao exercício de leitura crítica do gênero". (LOPES- ROSSI, 2002). Vejamos a seguir uma das produções após a intervenção.

\section{Produção 1 - Quadro 2}

Título: Escolas ficam em greve por falta de pagamento

Lead: Em Santa Rita os professores não estão indo para escola porque o prefeito não está pagando os salários dos professores. A sala de aula fica vazia. Não se sabe quando as aulas vão voltar.

Fonte: Segunda produção do aluno

Quem? Escolas

Que? Em greve

Quando? Momento atual

Onde? Santa Rita 
Observamos as respostas às perguntas que constitui o lead; Quem? Que? Quando? Onde? Assim, concluímos que o trabalho desenvolvido na produção do gênero notícia atendeu ao nosso objetivo de elaborar a produção por meio de sequência didática a partir do gênero discursivo/textual notícia.

Sendo assim, podemos reconhecer que a nossa intervenção foi necessária e proveitosa para superação de algumas dificuldades e consequentemente para a segunda produção mais elaborada. Agora com a segunda produção terminada, convidamos os alunos para conheceram um aplicativo digital o Microsoft Publisher (2010), onde fizemos a organização do jornalzinho. Essa adaptação contribuiu para aproximar suas notícias da realidade de um jornal impresso. Sendo a culminância a realização da exposição das produções no corredor da Escola onde os pais apreciaram e elogiaram os trabalhos realizados pelos filhos (as).

\section{Considerações finais}

Neste artigo, efetuamos algumas reflexões sobre a possibilidade de trabalhar com turmas em fase de alfabetização com o gênero discursivo/textual notícia. A proposta inicialmente tornou-se desafiadora, pois nessa fase de escolarização são muitas as dificuldades dos alunos, mas não é impossível ultrapassá-las e dar espaço a aprendizagem.

De acordo com a proposta de sequência didática que adotamos, seguimos as ações proposta por Lopes-Rossi (2002) e conseguimos fazer com que os alunos a partir de sua realidade produzissem seus textos.

Os alunos tiveram a oportunidade de conhecer as características do gênero textual / discursivo notícia, seu propósito comunicativo e principalmente conheceram o jornal impresso, visto que a maioria ainda não tinha folheado um jornal. Isso demonstra que na escola podemos criar situações de escrita em que o aluno desperte a atenção e identifique o gênero discursivo/textual no seu cotidiano social.

Estabelecer uma ponte entre a teoria e a prática é um grande desafio em sala de aula, devido às diversas dificuldades que encontramos no ambiente escolar, mas as produções que desenvolvemos durante esta pesquisa apontam para a necessidade e a possibilidade de desenvolver atividades de produção através de sequências didáticas, visto que são atividades organizadas e planejadas com um propósito definido. Trilhar o caminho do conhecimento implica não só aprender, mas, tornar a aprendizagem uma prática significativa em sala de aula. 
Os resultados obtidos revelam que é possível desenvolver um trabalho de produção escrita em turma em fase de alfabetização, voltados para a proficiência escrita dos alunos, desde que, o professor assuma um posicionamento comprometido em desenvolver atividades de produção com os gêneros discursivo/textuais, a exemplo da notícia, de forma significativa. Portanto, é imprescindível a formação acadêmica e a permanente formação continuada de professores (as) para atenderem a necessidade de uma educação básica de qualidade em nível nacional. Esperamos que o trabalho possa contribuir com a prática pedagógica no ensino de Língua Portuguesa e favoreça a continuidade de pesquisas na área de leitura e escrita a partir do gênero discursivo textual notícia.

\section{Referências}

BAKHTIN, M. Estética da criação verbal. São Paulo: Martins Fontes, 2011.

BAKHTIN, M.; Volochinov. Marxismo e filosofia da linguagem. 9. ed. São Paulo: Hucitec, 1999.

BRASIL. Parâmetros curriculares nacionais: língua portuguesa. Brasília: MEC/SEF, 2001.

BRASIL. Parâmetros curriculares nacionais: língua portuguesa. Brasília: MEC/SEF, 1997.

BRASIL. Secretaria de Educação Básica. Pacto Nacional pela alfabetização na idade certa. Ministério da Educação. Brasília: MEC, SEB, 2012.

BRAIT, Beth (org.). Bakhtin: dialogismo e polifonia. São Paulo: Contexto, 2013.

CAVALCANTE, Mônica M. Gêneros discursivos: os sentidos do texto. São Paulo: contexto, 2011.

DIONÍSIO, Ângela Paiva, MACHADO; Anna Rachel; BEZERRA, Maria Auxiliadora (Orgs.). Gêneros textuais \&ensino. Rio de Janeiro: Lucerna, 2005.

ERBOLATO, Mário L. Técnicas de codificação em jornalismo. 5. Ed. São Paulo: Ática, 1991.

FARIA Evangelina Maria Brito de. ALDRIGUE, Ana Cristina de Sousa. Linguagens: usos e reflexões. João Pessoa: Editora Universitária/ UFPB, 2008. V.3.

FERREIRA, A. Ler e escrever com prazer. In. MICOTTI, M.C. O. Alfabetização: entre o dizer e o fazer. (Org.). Rio Claro: Instituto de Biociências, UNESP, 2001. P. 125-140.

LOPES-ROSSI, M. A. G. Gêneros discursivos no ensino de leitura e produção de texto. Taubaté: Editora Cabral. Livraria Universitária. 2002.

SCHNEUWLY, Bernard \& DOLZ, Joaquim. Os Gêneros escolares: das Práticas de Linguagem aos Objetos de Ensino. In: DOLZ. Joaquim; SCHNEUWLY, Bernard. Gêneros 
orais e escritos na escola. Tradução e organização Roxane Rojo e Glaís Sales Cordeiro. Campina. SP: Mercado de Letras, 2004 [1997].

Recebido em 27 de setembro de 2019. Aprovado em 16 de novembro de 2019. 